\title{
The Cultivation of Intercultural Teaching Ability of Chinese International Education Majors
}

\author{
Xiaoxiao Li, Zhenzhou An \\ Yuxi Normal University \\ Yuxi, China \\ E-mail: lixiaoxiao@yxnu.edu.cn
}

\begin{abstract}
Intercultural teaching ability is an important ability of teaching of Chinese as a foreign language (TCFL). It includes three aspects, such as intercultural adaptability, intercultural expression and communication ability, and intercultural reflection ability. To intercultural teaching ability, a "four-inone" cultivation mode is proposed that includes perceptual training - experiential training - interactive training - reflective training. The use of "four-in-one" mode has been brought a positive effect on the cultivation of intercultural teaching ability of the students of Chinese international education through teaching practice.
\end{abstract}

Keywords- interculture; teaching ability; TCFL

\section{INTRODUCTION}

Intercultural communicative competence is an important ability for teachers of Chinese as a foreign language. In the international standard for Chinese teachers issued by the HHC / Confucius Institute, the teachers' intercultural communication skills are clearly defined. They not only require teachers to understand the knowledge of intercultural communication, but also translate them into specific practical skills in language teaching. This paper will discuss the teaching ability of Chinese teachers from the point of view of interculture, and give some suggestions on the training of the students of Chinese international education.

\section{INTERCULTURAL TEACHING ABILITY}

Intercultural teaching ability refers to the ability to achieve effective teaching in a global and intercultural context. It includes three aspects: intercultural adaptability, intercultural expression and communication ability, and intercultural reflection ability. Fig 1. shows this structure.

\section{A. Intercultural Adaptability}

Teaching of Chinese as a foreign language is different from other classes. Teachers and students are in different cultural backgrounds, and even students have different cultural backgrounds. Some forms of teaching which are common in Chinese classroom are no longer applicable or even subverted in the classroom of TCFL. For example, students are supposed to stand up when teachers come into the classroom and that is not feasible in some TCFL classes. Therefore, to organize teaching in a multicultural background, teachers are required to have a tolerance and debugging force in the encounter with cultural conflicts, but it is often not easy. I have interviewed some teachers who have been teaching Chinese in Thailand at the University of Thailand. Many teachers said that it was unbearable for students who were late for class and ate things in class in Thailand, and it would take about three months to adapt these habits. Some teachers could not even accept the negative behaviors of students even at the end of a year's term. If Chinese teachers want to carry out teaching normally when they encounter cultural conflicts, they must have strong intercultural adaptability and make a series of adjustments in their mentality, including the adjustment of their role to their own class, the leaders, participants or observers. Owning to judge the behavior of the foreign students following local custom, teachers do not take their own value judgment instead of the value judgment of the students. Only in this way can we organize the teaching and accomplish the teaching task smoothly in a good state of mind.

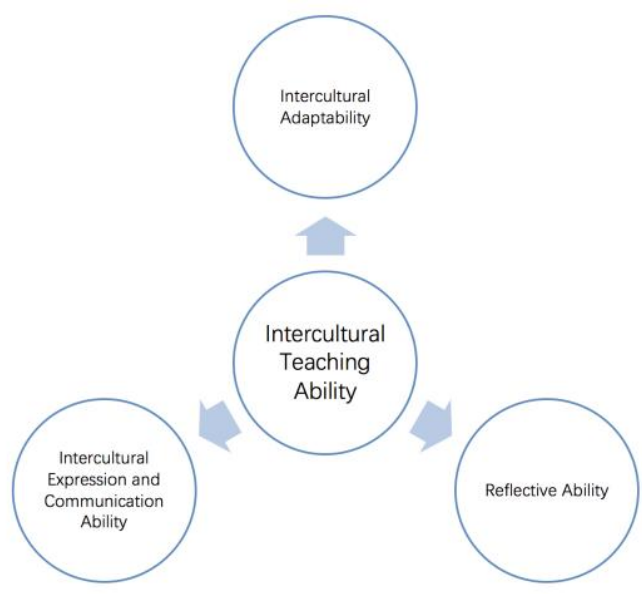

Figure 1. Structure of intercultural teaching ability

\section{B. Intercultural Expression and Communication Ability}

In addition to having good intercultural adaptability in the state of mind, the teachers of Chinese as a foreign language must also have strong intercultural expression and communication ability. This is an important condition for realizing the teaching goal and improving the teaching effect. It is also an important embodiment of the soft power of the teachers of Chinese as a foreign language. 
Intercultural expression and communication ability includes two levels mainly.

One is the ability of language transformation. The transformation refers to the conversion of various languages such as Chinese, students' mother tongue and medium language. In the primary stage, the Chinese level of students is limited, and sometimes teachers need to communicate with other languages. On the other hand, it refers to the ability of teachers to translate Chinese vocabulary and grammar between different levels of difficulty and flexibility according to the students' level freely. In explaining complex and advanced words, they can use the simple and primary vocabulary that the students have mastered, and can select the vocabulary appropriately, and make adjustments and skill transformation according to the students' hierarchical vocabulary, grammar and style.

Another is the ability to use non language to express and communicate. Non language refers to body behavior, gesture behavior, eye language behavior, body distance in conversation, silent language behavior, sound, intonation, volume, painting, image, dress and human posture physical signs and so on. These nonverbal behaviors can be used to exchange information, convey ideas, express feelings and attitudes. In the classroom of teaching Chinese as a foreign language, sometimes the explanation of the language is not clear and the communication effect can be easily achieved in non language. For example, when the word "Politeness" is explained to the students in Thailand, the teachers show two behaviors. One is that teachers join his hands together in class, make the most common Thai gift to the students, and another is that teachers walk past the students deliberately. (In the culture of Thailand, it is considered impolite to pass from others but not to bow down.) Compared to the two behaviors, the former is the performance of "Politeness", and the students quickly understand that the classroom atmosphere is active, and the students appreciate the vivid teaching of the teacher. It can be seen that learning some skills in non-verbal communication can help Chinese teachers improve their teaching effect and make teaching lively.

\section{Reflective Ability in Intercultural Teaching}

Teaching reflective ability refers to the ability of teachers to examine and analyze teaching ideas, teaching methods and teaching effects in their own teaching process rationally. It is an important ability that teachers should have. Due to the intercultural characteristics of teaching, teachers should also have the ability to reflect on intercultural thinking. There are often some "special" situations in the class of Chinese as a foreign language, for example, a very effective teaching method in China does not achieve the desired effect in the foreign Chinese class; the discussion topic carefully prepared by the teacher has received a cool response in the classroom; and even to practice the grammar for the students, it is specially designed for the students. The words let the students leave the field indignantly and so on. In this case, teachers should not only have the ability to control the current situation, but also have the ability to change the teaching plan flexibly, to reflect actively and rationally after the event. In order to prevent the recurrence of similar situations, we should always consider cultural factors and discover the process of events from an intercultural perspective and find the crux of the problem.

\section{CULTIVATION MODEL OF INTERCULTURAL TEACHING ABILITY}

We believe that the ability of intercultural teaching is very important for the teachers of Chinese as a foreign language, but many teachers in Chinese as a foreign language, especially the primary teachers or preparatory teachers, are very short about these abilities. Nowadays, many schools offering Chinese international education major specialize in providing students with overseas practice opportunities as a major feature. However, many of these students abroad have encountered problems such as classroom communication barriers, low teaching efficiency, and difficulties in teaching organization, which are largely due to the emergence of these problems that students lack the ability to intercultural teaching. It also reminds us that how to improve students' intercultural teaching ability should be an important part of cultivating students' comprehensive ability in the course of the cultivation of undergraduate students of Chinese international education major.

The cultivation of intercultural competence is not accomplished only by a few courses on intercultural communication. It should run through the whole process of training Chinese international education major, and the patterns and emphasis in each stage are not the same. In view of the various training stages of the Chinese International Education Major in Thailand, we proposed a "four-in-one" cultivation model for the training of intercultural teaching ability, namely, perceptual training - experiential training interactive training - reflective training.

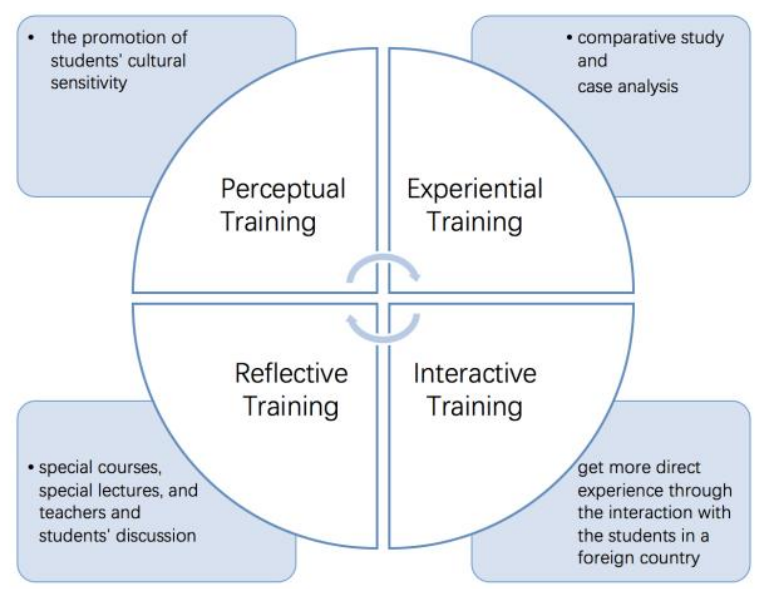

Figure 2. A "four-in-one" cultivation model for the training of intercultural teaching ability

\section{A. Perceptual Training}

As the students have just entered the university, they have not established a strong professional consciousness, and most 
of them have no experience in intercultural teaching. Therefore, in this stage, perceptual methods are to raise the emphasis of the cultivation of intercultural teaching ability on the promotion of students' cultural sensitivity. In the first year of the university, some basic language courses and cultural courses are offered, such as modern Chinese, ancient Chinese, English, Thai, Chinese and foreign culture, and we think that these courses should be different from the Chinese language and literature major or the related courses in English and Thai In the teaching of these courses, the teachers should consciously add some Chinese and foreign language and cultural contrast from an intercultural perspective. For example, in modern Chinese or Thai classes, it is not simply to teach Chinese knowledge or Thai, but to combine the two languages, from pronunciation, word formation, grammar and language. A comparative analysis of the culture and other aspects of the infiltration, such as the comparison of the tone value of the Chinese tone and the Thai tone, and the similarities and differences between the Chinese sentence structure and the Thai sentence structure, help the students cultivate a "double culture consciousness" in the process of perceiving the cultural differences of the language.

\section{B. Experiential Training}

The second stage of experiential training is usually in the second grade of the university, when the students begin to contact more and more core professional theory courses, such as the introduction of teaching of Chinese as a foreign language, teaching methods of teaching of Chinese as a foreign language and so on. These are the courses that students really walk into the category of teaching of Chinese as a foreign language. In the teaching of these courses, besides theoretical teaching, comparative study and case analysis are also important. In the course of case study, teachers should also enlighten students from the perspective of intercultural teaching in addition to students' experience and study of teaching of Chinese as a foreign language, so that students can establish the teaching of Chinese as a foreign language in a intercultural environment from the beginning. Sometimes, we can also select cases for intercultural communication. The source of the case is multifaceted, which can be provided in the reference book and can be reflected in the film and television works (such as the Thailand film "Hello, Galileo", the American film "Anna and the king" etc.), and it can also be from real life (for example, senior students' internship Diary). The aim is to help students to accumulate some indirect experiences in intercultural teaching. If the conditions are allowed, it is best to provide some practical opportunities for students and let the students experience intercultural communication and intercultural teaching in the Chinese environment.

\section{Interactive Training}

In the third stage, students begin to go to Thai to practice, that is to say, intercultural teaching enters the actual stage. They should teach Chinese in the Thai environment, and will also get more direct experience through the interaction with the students in Thailand. For second language learners, longterm immersion in the target language environment is helpful to improve the target language proficiency and feel the culture of target language. In the same way, the intern teachers in the mother tongue are able to understand the Thai language and Thailand culture more directly, and improve their understanding of the differences between Chinese and Thai cultures, and also to improve their intercultural sensitivity. If the students learn an indirect experience with universality in the prior experience training stage, at this stage, students will gain more microscopic and specific direct experience. At the same time, students no longer enjoy the former way of teacher's instruction. They should be in a different cultural environment lonely. Students will experience "honeymoon", "depression", or even "difficult period" and these require an intern instructor to strengthen the real time interactive guidance to the students. In the form of remote (E-mail, network real-time communication, etc.), the students can communicate and guide the students from the aspects of teaching skills, communication strategies and psychological counseling, so that students can get through the "adjustment period" and finally reach the "suitable period".

\section{Reflective Training}

Through the study and practice of above three stages, the students have accumulated a lot of theoretical knowledge and have some practical experience in the Chinese teaching in the intercultural background. Posner, a famous American scholar, has put forward the formula of teacher's growth rule, that is, "experience + reflection $=$ growth". As the last stage of the training of intercultural teaching, the central task of the fourth stage is to train students to reflect on the experience gained before the intercultural communication, so as to promote the students' professional growth. Through a variety of forms, such as special courses, special lectures, and teachers and students' discussion, we can use the method of case based on teaching reflection to collect and collate the cases in the practice stage before the students, and let the students combine their own cases under the guidance of the teachers, and make the ideas and doubts about the decision at that time, and thus make the result. The way of treatment is elaborated and discussed and explored with teachers and other students. Through this interactive and open way of learning, on the one hand, it can improve the ability to analyze and solve problems, and more importantly, let the students learn how to reflect on teaching and to think and judge independently in the teaching of Chinese in the future.

\section{CONCLUSION}

The cultivation of intercultural teaching ability is not an easy task. The training unit of Chinese international education major should put it through the whole process of talent training, and combine the characteristics of different stages in the process to formulate effective training programs so that the students of the Chinese international education major can have a better intercultural teaching before entering the job.

\section{REFERENCES}

[1] Y. Chen, "On Reform Strategies of College English Cross-cultural Teaching in the Background of One Belt and One Road," Journal of 
Changsha University of Science and Technology (Social Science), vol.11, 2018

[2] F. Li, "Construction of teaching mode of intercultural communication courses oriented by TCM overseas publicity," Education of Chinese Medicine, No. 2, 2018.

[3] C. H. Chen, "A Study of the Cultural Character of English Subject Literacy," Theory and Practice of Education, No. 8, 2018.

[4] J. G. Cai , "Contextualization and Specification:A Sensible Approach in Tertiary English Education of New Era," Journal of Zhejiang International Studies University, No. 2, 2018.

[5] J. J. Weng, "Construction and Practice of Experiential Cultural Teaching Model in Practical English in Vocational Colleges- A Case
Study of Zhejiang International Maritime College," Journal of Wenzhou Vocational and Technical College, No. 1, 2018.

[6] H. L. Zhang, Y. D. Yu, X. T. Shen, "Contests as an intercultural competence assessment method: A case study of the SFLEP Shanghai Intercultural Competence Contest," Foreign Language World, No. 1, 2018.

[7] Y. Hu, X. R. Wang, "Problems in the Stratified Teaching Model for College English and the Countermeasures," Journal of Anhui Electrical Engineering Professional Technique College, No. 3, 2011.

[8] L. S. Xu, "Intercultural Competence Revisited," Journal of Zhejiang University(Humanities and Social Sciences), No. 3, 2011. 